\title{
FREQUENCY SPECTRUM AND VARIABILITY ANALYSIS FOR BIG DATA IN GEOLOGICAL SPACE -TAKING DRILLING BIG SAMPLE DATA IN ORDOS BASIN AS A CASE STUDY
}

\author{
CAO, M. X. ${ }^{*}-$ LU, L. J. ${ }^{2}-$ XIN, S. ${ }^{2}$ \\ ${ }^{1}$ College of GeoExploration Science and Technology, Jilin University, Changchun 130021, \\ China \\ ${ }^{2}$ College of Earth Sciences, Jilin University, Changchun 130061, China \\ *Corresponding author \\ e-mail: caomx_lovely@163.com
}

(Received 23 ${ }^{\text {rd }}$ Feb 2019; accepted $3^{\text {rd }}$ May 2019)

\begin{abstract}
The scientific problem of fusion analysis for geospatial big data is to obtain the structure, composition, spatial distribution and variation law of geological bodies from interdisciplinary data. The key technology is to carry out a geospatial three-dimensional reconstruction and visualization, and perform spatial analysis, prediction and decision. Spatial distribution and variability analysis of Ordos sandstone uranium mining is an important concern for uranium formation research. This study is based on big sample data of typical drilling and constructs a digital frequency spectrum model reflecting uranium oxidation-reduction space and lithofacies combination relationship, to describe uranium change of Zhiluo formation strata combination and spatial coupling relationship with the surrounding rock. Modeling process involves a series of key assessments which are structure analysis for big sample data of typical drilling, scale calculation, digital frequency spectrum and variation function principle, geological interpretation. Using stratum as minimum geological unit by spatial frequency spectrum calculation, this study can directly make frequency spectrum synthesis calculation with different levels such as stratum combination, sedimentary facies combination and basin, so as to build geological spatial digital feature model, which can be used as a basis for quantitative analogy and extrapolation prediction in the northern sandstone uranium basin.
\end{abstract}

Keywords: Geospatial big data, fusion analysis, big sample space scale, digital frequency spectrum, variation function

\section{Introduction}

The geological space is the complex material accumulation body with mixed characteristics produced in the upper crust. The geoscience big data based on geological space has four characteristics: complexity, heterogeneity, periodicity and extensiveness. Processing analysis of geoscience big data belongs to complexly giant system. The scientific essence of geoscience big data research is to realize geological space abstraction through geological spatial distribution and variability exploration; to establish geoscience space model, and carry out geological process simulation, then implement geological space prediction and decision-making, which serves the two major geosciences needs of mineral resource prediction and geological hazard warning. Due to the particularity of the geological space, it brings more uncertainty and cannot fully (or very well) express geological entity information for space modeling of geological big data. The major theoretical and technical issues for complex analysis of geospatial big data include: discussion of multi-heterogeneity and synergy of geological big data, discussion of randomness and chaotic nature of geological space, science division of geological space, cross-fusion of geological big data, complex modeling, 
spatial computing visualization, spatial prediction and spatial decision-making, etc. (Zhang and Zhou, 2017; Zhou et al., 2018, 2017).

Ordos continental uranium-bearing basin is giant accumulation area of uranium mining in north China, and Zhiluo formation in continental sedimentary construction is stratum combination with uranium-bearing specificity (Liu et al., 2013; Min et al., 2005; Jiao et al., 2016; Yang et al., 2015). Distribution variation of uranium mining space has a close relationship with sedimentary construction evolution, and borehole logging data is the important data set to reflect vertical lithology combination of the basin and the change of its physical properties; the logging data is divided into two types of direct uranium anomaly data and indirect associated data (Feng et al., 2016; Hao et al., 2015; Jiang et al., 2016; Liu et al., 2016; Yi et al., 2015). Application of logging data to depict digital features of uranium-bearing construction, which is not only very important for identifying change rule of uranium-bearing rock series of sedimentary facies and other sedimentary stratum combination, but also is important for identifying uranium-bearing characteristics of basin space (Ahmed and Arnous, 2015; Cai et al., 2015; Li et al., 2015; Luo et al., 2015). Therefore, the quantitative analysis of basin sedimentary facies, sedimentary construction, and uranium-bearing series is a hot and difficult problem for sandstone type uranium deposits assessment.

From the angle of geological analysis, basin sedimentary construction represents oxidation-reduction environment space of sedimentary environment and uranium element, and the smallest unit of sedimentary construction is stratum, different forms of stratum combination reflect overall characteristics of sedimentary facies and sedimentary construction, in general, geological information contained in these variation characteristics are drowned out by logging data (Guo and Xue, 2014; Wu, 2005; Zhao et al., 2015). Sometimes, it is impossible to directly extract uranium variation information from logging data, which objectively requires make systematic, comprehensive analysis about data structure and digital feature for logging data, and this is the objective of this study.

Uranium-bearing construction or lithofacies combination is constituted of different stratums. According to a certain space order relation, geologic body is constituted, and each stratum lithology has dependent and inheritance with overlying stratum, underlying stratum lithology in space, which in overall presents correlation and additivity (Li, 2012; Wang et al., 2014; Zhu, 2013). Therefore, digital feature model of basin sedimentary space should have structure and extensionality, and these are general principles which basin digital feature analysis should follow, which shows that analysis calculation of basin digital features depends on space order and logic recursive relationships of the construction, sedimentary facies, and uranium-bearing rock series.

\section{Materials and methods}

Every stratum geologic body in basin construction is deemed as independent monomer, and its thickness is L, logging data samples according to equal interval, so each stratum with different depth gets different number of samples, in special cases encryption interpolation processing for sample number of some stratum are made. Thereby a digital frequency spectrum model is established, the detailed process is as follows. 


\section{Sample capacity determination}

The average depth of all boreholes in the Ordos basin is in the range of 500-700 m, the sampling interval in the logging is generally $5 \mathrm{~cm}$, and interpolation processing can reach $1 \mathrm{~cm}$. The number of logging samples for each borehole can reach at least 10000; logging parameters of each sample point respectively contain four items, which are natural gamma, caliper, density, and resistivity. These parameters also contain 25 lithology parameters, which are all nominal type geological data. According to sample matching scale analysis, four logging curves data have a unique representation under the target association significance of the uranium bearing could be informed. Therefore, four logging curves as main variable parameters were made, and radioactive $r$ spectrum parameter was used as target variable, other three curve parameters as independent variables. First, causal relationship model between target variable and independent variables was established, and calculated independent weights of each variable under the condition with best curve fitting, and calculated correlation weight of target variable to satisfy the criterion of maximum correlation between independent variables combination and target variable. Next combination calculation for independent weights and correlation weight of each sample were made, and then obtained spatial scale value of the sample, thus formed the sample sequence.

The specific process was as follows:

Obtained borehole logging data matrix, and made the following translation transforms:

$$
x_{i j}=\frac{x_{i j}^{*}-\min \left(x_{l j}^{*}\right)}{\sigma_{j}} \quad 1 \leq l \leq n, \quad i=1,2, \cdots, n, \quad j=1,2, \cdots m
$$

Here, $x_{i j}^{*}$ was the original logging data, $n$ was the sample size and constituted a computing matrix $X=\left(x_{i j}\right)_{n \times m}=\left(X_{1}, X_{2}, \cdots, X_{m}\right)$, among $X_{1}, X_{2}, \cdots, X_{m}$ was the independent variables. In this study, $m=3$; and target variable $Y=\left(Y_{1}, Y_{2}, \cdots, Y_{n}\right)^{\prime}$.

The problem of this study was to compute independent weights of independent variable and correlation weight of target variable, so the following causal relationship model were established, as follows:

$$
\left\{\begin{array}{c}
y=b_{0}+\sum_{j=1}^{m} b_{j} X_{j} \\
y=b_{0} \exp \left[\sum_{j=1}^{m} b_{j} X_{j}\right] \\
y=b_{0} \exp \left[\sum_{j=1}^{m} b_{j} X_{j}\right]^{2}
\end{array}\right.
$$

In all above equations, least-squares solution or optimal simulation solution was strived, and chose most remarkable equation as regression equation, then calculated partial regression square sum of each independent variable: $V_{j}=\frac{b_{j}^{2}}{c_{j j}} \quad j=1,2, \cdots, m$, 
here, $b_{j}$ was regression coefficients of remarkable regression equation, $c_{j j}$ was main diagonal elements of inverse matrix of regression equation coefficient matrix, $V_{j}$ would be defined as independent weights of corresponding variables $X_{j}$.

Considered the contribution of independent variables combination for target variable, correlation weight of target variable was calculated according to the following transformation: supposed constant $\alpha, \beta$, and satisfied $\alpha+\beta=1$, made:

$$
q=\sum_{i=1}^{n}\left(\alpha y_{i}-\beta \sum_{j=1}^{m} V_{j} X_{j}\right)^{2} \rightarrow \min
$$

This meant that it had least fitting relationship between target variable and square for weighted residuals of independent variable combination, there had to be: $\frac{d q}{d \alpha}=0$, and got:

$$
\alpha=\frac{\sum_{j=1}^{m} V_{j} \overline{X_{j}}}{\bar{y}+\sum_{j=1}^{m} V_{j} \overline{X_{j}}}
$$

Then defined sample space scale value of four logging curves were: $d_{i}=\alpha y_{i}+\beta \sum_{j=1}^{m} V_{j} \overline{X_{j}} \quad, \quad i=1,2, \cdots n$ and gained spatial scaling sequence set: $D=\left(d_{1}, d_{2}, \cdots d_{n}\right)^{\prime}$.

\section{Samples spatial spectrum density calculation}

For sample $D$ sequence, according to the following process to calculate spatial spectral density of samples (Cui and Singh, 2016; Khalid et al., 2013; Lu and Liu, 2015; Ma et al., 2012; Mariotti et al., 2014; Silbert and Thomas, 2013), here had two cases:

Big sample scale sequence of individual geology body

Calculation procedure was as follows:

Supposed $D$ sequence of a stratum sample scale as stable process, which had: $\{D(i), i \in R\}$.

Defined Fourier transform of $D(i)$ as spectral function, as follows:

$$
F_{D}(\omega, I)=\int_{-I}^{I} D(i) e^{-j \omega i} d i
$$

Defined $S_{D}(\omega)=\lim _{I \rightarrow \infty} \frac{1}{2 I} E\left\{\left|F_{D}(\omega, I)\right|^{2}\right\}<\infty$ as spatial spectral density of $D(i)$, this was distribution relationship of $D(i)$ about frequency $\omega(\omega=2 \pi f$ is angular frequency). 
Further defined autocorrelation function of $D(i)$ (Chen, 2009), there was:

$$
\begin{aligned}
R_{D}\left(i_{1}, i_{2}\right) & =E\left[D\left(i_{1}\right) D\left(i_{2}\right)\right] \\
& =\int_{-\infty}^{\infty} \int_{-\infty}^{\infty} D_{1} D_{2} f\left(D_{1}, D_{2} ; i_{1}, i_{2}\right) d D_{1} d D_{2}
\end{aligned}
$$

This was autocorrelation function of $D(i)$, such as $D(i)$ is stable process, so $R_{D}\left(i_{1}, i_{2}\right)$ in unrelated to choice of location $i_{1}$ and $i_{2}$, only related to the size of $\left(i_{2}-i_{1}\right)$. Supposed $i_{2}-i_{1}=\tau$, then autocorrelation function was represented as $R_{D}(\tau)$, therefore, which was also called as spatial variation function.

The relationship expression between spatial spectral density function $S_{D}(\omega)$ and spatial variation function $R_{D}(\tau)$ :

$$
\left\{\begin{array}{c}
S_{D}(\omega)=\int_{-\infty}^{\infty} R_{D}(\tau)^{-j \omega \tau} d \tau \\
R_{D}(\tau)=\frac{1}{2 \pi} \int_{-\infty}^{\infty} S_{D}(\omega)^{j \omega \tau} d \omega
\end{array}\right.
$$

Here, it meant that $S_{D}(\omega)$ and $R_{D}(\tau)$ were mutually Fourier inverse transform pair. $S_{D}(\omega)$ represented concentration degree index of space attribute set in the same geology body, which was domain function about frequency, this set was also called spectrum, and represented unique digital features of this geology body.

\section{Big sample scale sequence of two geology bodies}

Calculation procedure was as follows:

Above $D(i)$ sequence represented geology monomer, for scale sequence $D(i)$ and $H(i)$ of two geology bodies, cross-spectral density and crosscorrelation function was calculated (Hotelling, 2012; Lei et al., 2011; Liang et al., 2011; Lv et al., 2011; Xie et al., 2011), this was:

$$
S_{D H}(\omega)=\lim _{I \rightarrow \infty} \frac{1}{2 I} E\left\{F_{D}(\omega, I) F_{H}(\omega, I)\right\}
$$

Further there was:

$$
\begin{gathered}
S_{D H}(\omega)=\int_{-\infty}^{\infty} R_{D H}(\tau) e^{-j \omega \tau} d \tau \\
R_{D H}(\tau)=\frac{1}{2 \pi} \int_{-\infty}^{\infty} S_{D H}(\omega) e^{j \omega \tau} d \omega
\end{gathered}
$$


It could be seen that these two were Fourier inverse transform pair. It should be pointed out that establishing of cross-spectral density and cross-correlation function should be carried out under the premise that two geology bodies should have spatial correlation.

\section{Additive operation of big sample space spectrum density}

When two or more than geology bodies need to make cumulative calculation of spectral density, the formula could be $Z=\bigcup_{i=1}^{p} D_{i}$, which expressed that $P$ geology bodies superimposed. Therefore, combined spectral density after superimposing was $S_{Z}(\omega)=\sum_{i=1}^{p} S_{D_{i}}(\omega)$, and average variation function of the geology body after superimposing was $R_{Z}(\tau)=\int_{-\infty}^{\infty} S_{z}(\omega) e^{-j \omega \tau} d \tau$.

\section{Synthesis calculation for stratum combination}

It is well known, all substance has vibration frequency, but vibration frequency of irregular geology body such as geological space is unable to estimate, this study can only start from multiple observation data to estimate. In this sense, spatial frequency spectrum function is expressed as frequency domain function, which completely can satisfy superposition operation conditions, and it also has the function of transforming into spatial domain, so as to make variability analysis.

Stratum combination (construction, sedimentary facies and rock facies) analysis is an indispensable part for basin analysis. Spatial frequency spectrum of geology body belongs to non-dimensional measurement, which can be made additive operation in the mathematical sense. Spatial frequency spectrum of different geology bodies exists the difference in the magnitude and structure. Oxidation, oxidation and reduction, boundary classification of reduction space for basin uranium involves synthesis calculations problem of spatial frequency spectrum, therefore according to the different levels of stratum combination to make synthesis calculations of spatial frequency spectrum, and constitute the whole content for digital features analysis of stratum, sedimentary facies, sedimentary formation and even the whole basin.

About superposition conditions of stratum, apart from according to geological methods such as sedimentary facies analysis, etc., also judge from the cross-correlation function and cross-spectral density function defined by this study. Generally, higher cross-correlation function in two stratums can be considered to make spectrum synthetically calculation. Cross-correlation function can also be used as the basis for three-division space.

\section{Results}

\section{Background}

Logging data of ZKA-7 borehole in the A exploration line of Daying uranium area in Ordos basin is used in this study, the distribution of boreholes in the A exploration line is shown in Figure 1. Then trial calculation based on above models was make, the result is as follows. 


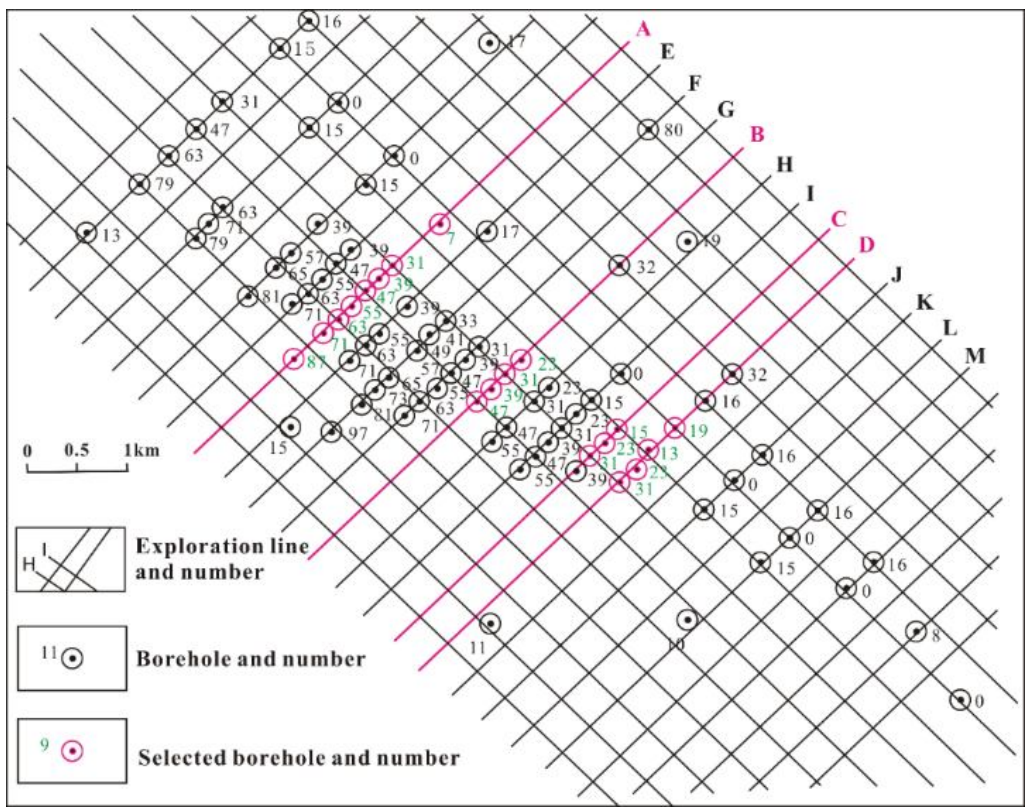

Figure 1. Boreholes distribution in the A exploration line

Spectrum density curves and spatial variation curves of each section interval for ZKA-7 borehole in the A exploration line are shown in Figures 2 and 3; 20-716 m variation comprehensive curve is shown in Figure 4. It should be noted that the depth markings on the figure do not correspond to the exact location, and it represents only the general characteristics of some section interval.
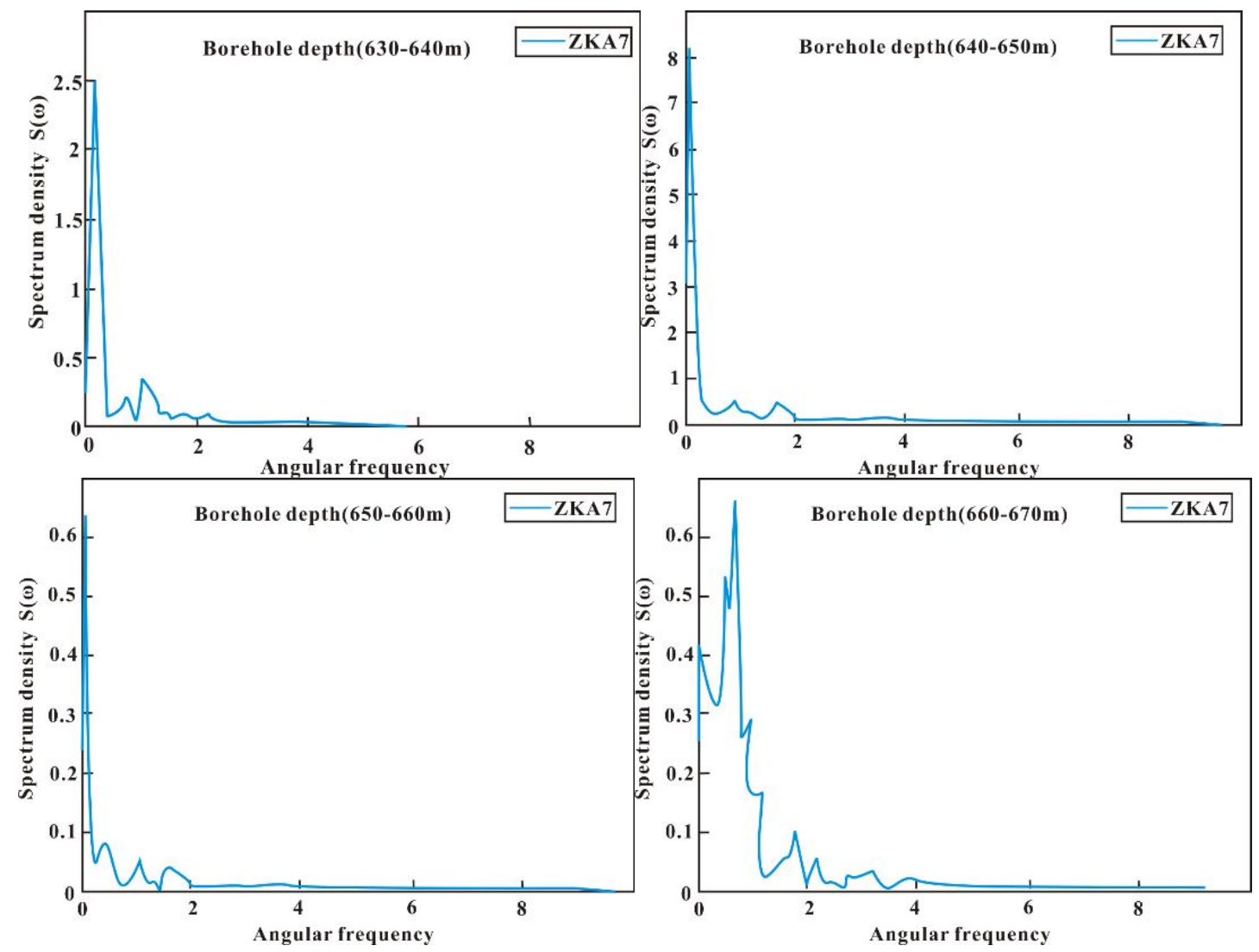

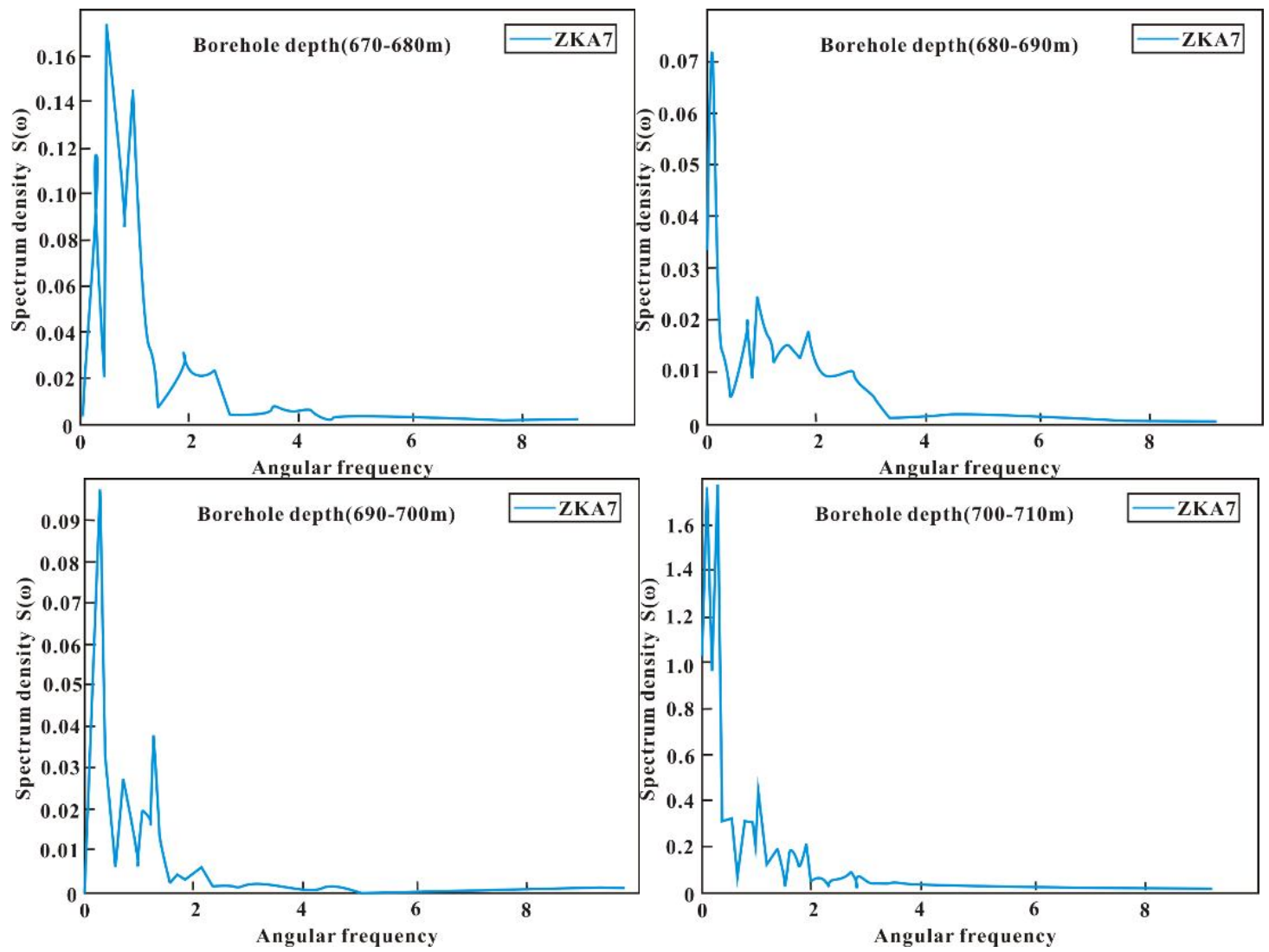

Figure 2. Spectrum density curves of A drill for 630-710 m
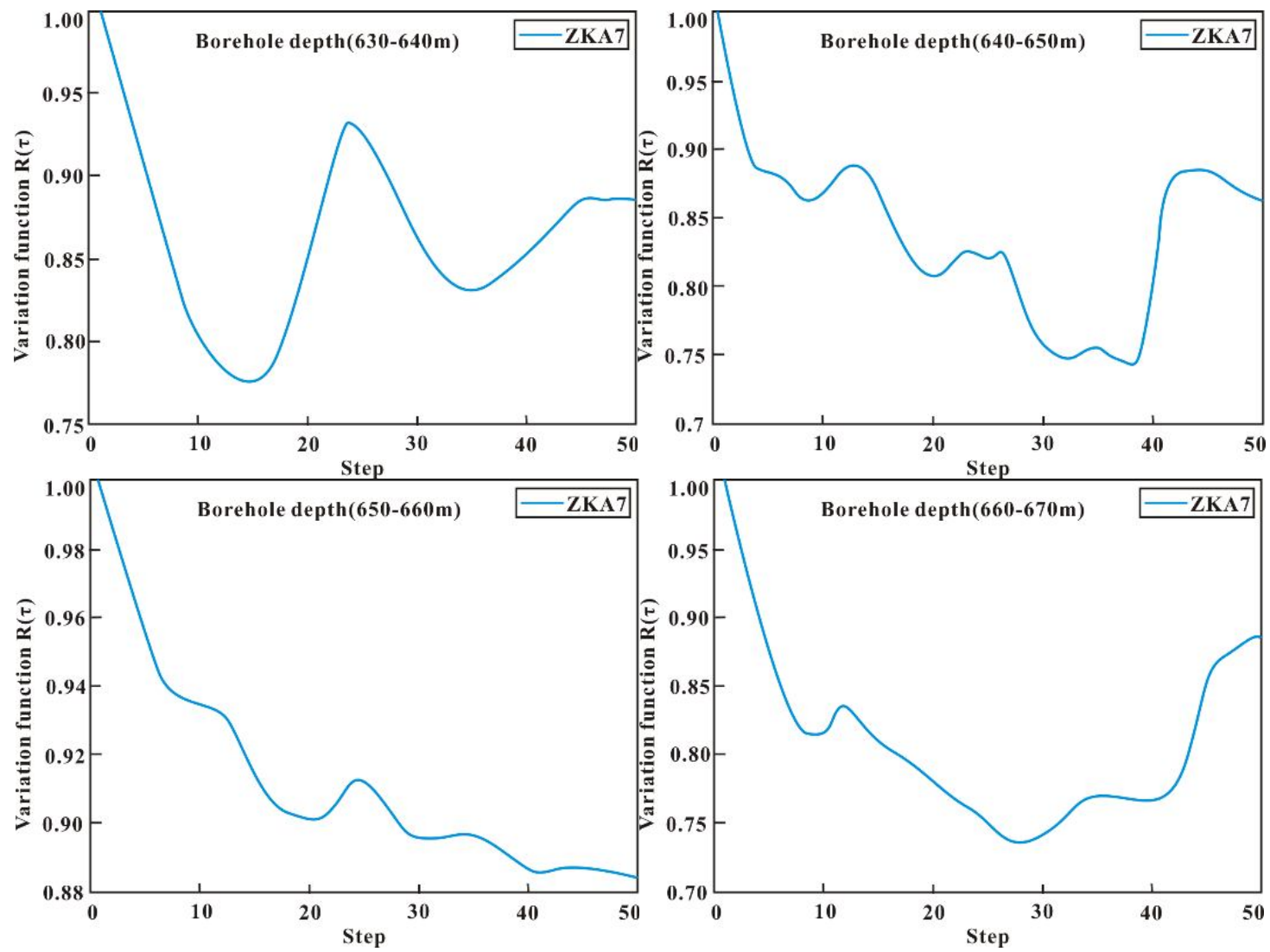

APPLIED ECOLOGY AND ENVIRONMENTAL RESEARCH 17(4): 7927-7941.

http://www.aloki.hu • ISSN 15891623 (Print) • ISSN 17850037 (Online)

DOI: http://dx.doi.org/10.15666/aeer/1704_79277941

(c) 2019, ALÖKI Kft., Budapest, Hungary 

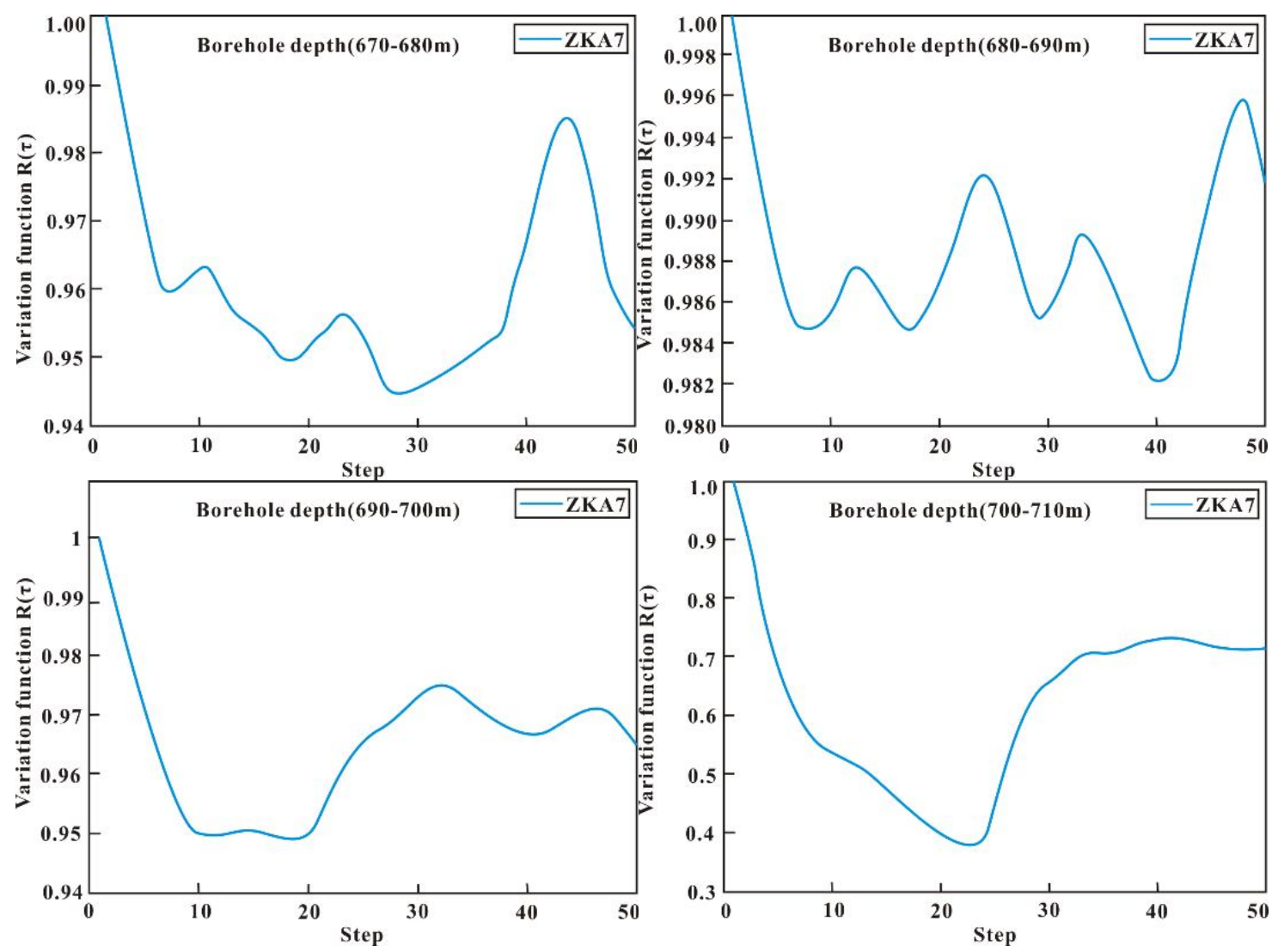

Figure 3. Variation curves of A drill for $630-710 \mathrm{~m}$

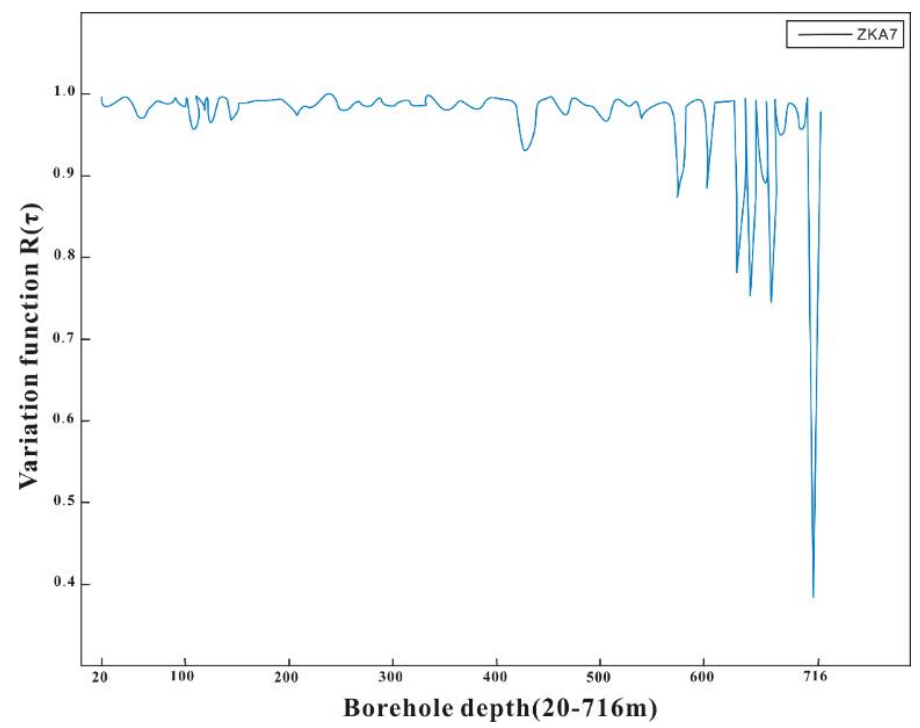

Figure 4. Comprehensive variation curve for ZKA-7 borehole (20-716 m)

In order to express the distribution of variation function $R_{x}\left(\tau_{n}\right)$ of all boreholes in $\mathrm{A}$ exploration line, specifically it will synthesize all variation curves of all boreholes in A exploration line, and finally generate variation comprehensive curve of the whole borehole, as shown in Figure 5. 


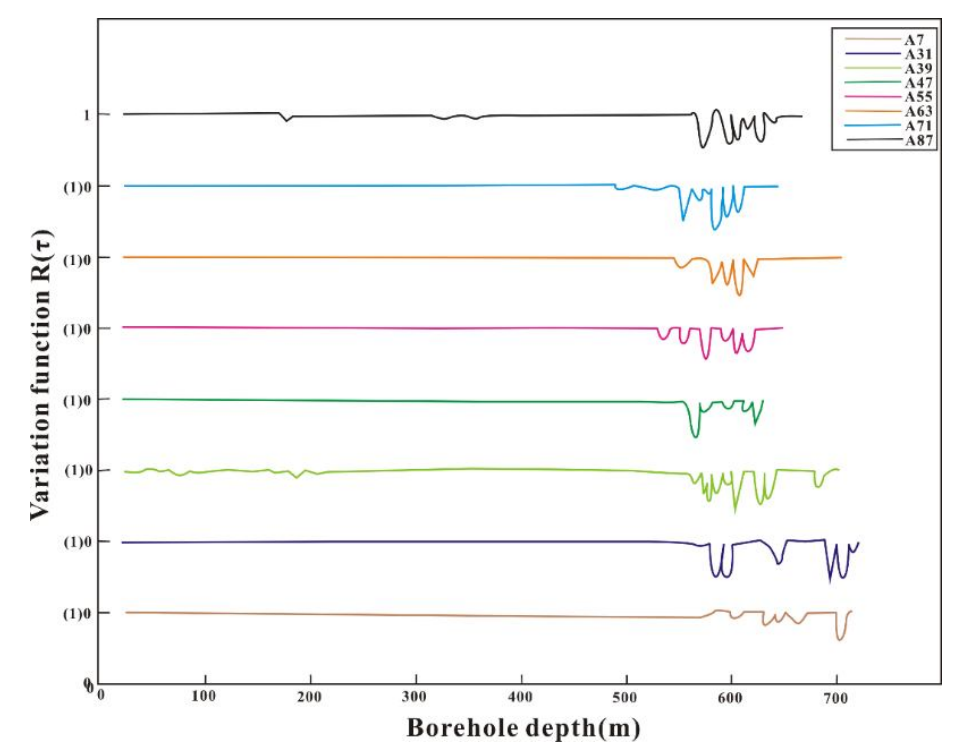

Figure 5. Comprehensive variation curves for 8 boreholes in A exploration line

In order to express the variation characteristics of lithologic assemblages of different strata at different depths, according to the statistical calculation of A borehole, $50 \mathrm{~m}$ is used as the interval standard, and the spatial spectrum density value of each section and the corresponding spatial variation value are calculated respectively. This part focuses on the section of 630-710 $\mathrm{m}$ with gamma anomaly characteristic.

\section{Discussion}

The spatial spectrum density curves represent the aggregate degree of the uranium mineralization factor (attribute set) combined by four parameters in the unit space measure (depth distance), which reflects the comprehensive intensity index of regional uranium mineralization, and call as generalized spatial attribute density (hereinafter referred to as density). This kind of parameters combination indicates a measure of the comprehensive information, which is more comprehensive than traditionally measured by single natural gamma or quantitative gamma, and the identified information is more reliable.

Due to the imbalance of geological actions in the region, resulting in the imbalance of comprehensive strength index or density distribution for the uranium mineralization, so the spatial distribution sometimes shows singularity characteristics, which is socalled anomaly phenomenon. The singularity characteristics or anomaly phenomenon is an important research content for spatial data distribution, and its scientific nature reflects the intensity change of geology action caused by regional environment, such as: magma intrusion with heat source intrude into the region is selective, so mineralization enrichment of the polymetallic elements formed during the process of magma emplacement is imbalanced.

From Figure 2 it can be seen that distribution state of uranium mineralization factor density. Spectrum density curves of uranium mineralization factor for logging data about the entire borehole shows that the oscillation form, but oscillation frequency and density amplitude (ie, amplitude value, which is the corresponding function value) are different as different depth. Each spectrum density curve shows the frequency closer to 
0 points, the greater the marginal density, where the marginal density can also be identified as the maximum density distribution of this section, and with the frequency increases, the density gradually decay, which is the unique characteristics of the model algorithm.

From the view of section, the amplitude of the spectrum curves for the 65 sections (20-630 m, 670-700 $\mathrm{m}$ and $710-716 \mathrm{~m})$ in the calculation is smaller, usually fluctuates between $0.01 \sim 0.35$, and the features of density variation is not obvious, and the scale average in these sections is also lower, as shown in Table 1 and Figure 4. But the amplitude for the five sections $(630-670 \mathrm{~m}, 700-710 \mathrm{~m})$ is larger, fluctuates between 0.7 and 9 , as the frequency changes with same interval, the change of the density is also larger, and original scale average for these sections is also higher (Table 1). The comparison shows: the amplitude of the spectrum curves, original scale average for these five sections are significantly higher than other 66 sections of the ZKA-7 borehole. This can be understood as that in areas where the density is high, the density changes significantly and original scale average is also high, the comprehensive intensity of uranium mineralization is stronger. It is shown that these uranium combinations under the conditions of the redox environment achieve the best state, very conducive to precipitation mineralization for uranium element.

Table 1. Original scale average in different depth interval

\begin{tabular}{c|c|c|c|c|c|c|c|c|c}
\hline $\begin{array}{c}\text { Depth } \\
\text { interval }\end{array}$ & $\begin{array}{c}\text { Original } \\
\text { scale } \\
\text { average }\end{array}$ & $\begin{array}{c}\text { Depth } \\
\text { interval }\end{array}$ & $\begin{array}{c}\text { Original } \\
\text { scale } \\
\text { average }\end{array}$ & $\begin{array}{c}\text { Depth } \\
\text { interval }\end{array}$ & $\begin{array}{c}\text { Original } \\
\text { scale } \\
\text { average }\end{array}$ & $\begin{array}{c}\text { Depth } \\
\text { interval }\end{array}$ & $\begin{array}{c}\text { Original } \\
\text { scale } \\
\text { average }\end{array}$ & $\begin{array}{c}\text { Depth } \\
\text { interval }\end{array}$ & $\begin{array}{c}\text { Original } \\
\text { scale } \\
\text { average }\end{array}$ \\
\hline $20-30 \mathrm{~m}$ & 1.12 & $30-40 \mathrm{~m}$ & 1.18 & $40-50 \mathrm{~m}$ & 1.16 & $50-60 \mathrm{~m}$ & 1.18 & $60-70 \mathrm{~m}$ & 1.11 \\
$70-80 \mathrm{~m}$ & 1.17 & $80-90 \mathrm{~m}$ & 1.21 & $90-100 \mathrm{~m}$ & 1.32 & $100-110 \mathrm{~m}$ & 1.04 & $110-120 \mathrm{~m}$ & 1.17 \\
$120-130 \mathrm{~m}$ & 1.26 & $130-140 \mathrm{~m}$ & 1.25 & $140-150 \mathrm{~m}$ & 1.22 & $150-160 \mathrm{~m}$ & 1.13 & $160-170 \mathrm{~m}$ & 0.99 \\
$170-180 \mathrm{~m}$ & 1.20 & $180-190 \mathrm{~m}$ & 1.19 & $190-200 \mathrm{~m}$ & 1.32 & $200-210 \mathrm{~m}$ & 1.15 & $210-220 \mathrm{~m}$ & 1.04 \\
$220-230 \mathrm{~m}$ & 1.25 & $230-240 \mathrm{~m}$ & 1.44 & $240-250 \mathrm{~m}$ & 1.25 & $250-260 \mathrm{~m}$ & 1.17 & $260-270 \mathrm{~m}$ & 1.41 \\
$270-280 \mathrm{~m}$ & 1.46 & $280-290 \mathrm{~m}$ & 1.50 & $290-300 \mathrm{~m}$ & 1.27 & $300-310 \mathrm{~m}$ & 1.20 & $310-320 \mathrm{~m}$ & 1.17 \\
$320-330 \mathrm{~m}$ & 1.28 & $330-340 \mathrm{~m}$ & 1.33 & $340-350 \mathrm{~m}$ & 0.97 & $350-360 \mathrm{~m}$ & 0.93 & $360-370 \mathrm{~m}$ & 1.06 \\
$370-380 \mathrm{~m}$ & 1.22 & $380-390 \mathrm{~m}$ & 1.20 & $390-400 \mathrm{~m}$ & 1.11 & $400-410 \mathrm{~m}$ & 1.05 & $410-420 \mathrm{~m}$ & 1.16 \\
$420-430 \mathrm{~m}$ & 0.89 & $430-440 \mathrm{~m}$ & 0.68 & $440-450 \mathrm{~m}$ & 1.07 & $450-460 \mathrm{~m}$ & 1.11 & $460-470 \mathrm{~m}$ & 1.13 \\
$470-480 \mathrm{~m}$ & 1.01 & $480-490 \mathrm{~m}$ & 1.03 & $490-500 \mathrm{~m}$ & 0.91 & $500-510 \mathrm{~m}$ & 1.07 & $510-520 \mathrm{~m}$ & 1.20 \\
$520-530 \mathrm{~m}$ & 1.13 & $530-540 \mathrm{~m}$ & 1.22 & $540-550 \mathrm{~m}$ & 1.08 & $550-560 \mathrm{~m}$ & 1.13 & $560-570 \mathrm{~m}$ & 1.12 \\
$570-580 \mathrm{~m}$ & 1.24 & $580-590 \mathrm{~m}$ & 1.10 & $590-600 \mathrm{~m}$ & 1.21 & $600-610 \mathrm{~m}$ & 1.38 & $610-620 \mathrm{~m}$ & 1.17 \\
$620-630 \mathrm{~m}$ & 1.20 & $630-640 \mathrm{~m}$ & 2.89 & $640-650 \mathrm{~m}$ & 4.47 & $650-660 \mathrm{~m}$ & 1.45 & $660-670 \mathrm{~m}$ & 2.49 \\
$670-680 \mathrm{~m}$ & 1.75 & $680-690 \mathrm{~m}$ & 1.42 & $690-700 \mathrm{~m}$ & 1.31 & $700-710 \mathrm{~m}$ & 2.43 & $710-716 \mathrm{~m}$ & 1.49 \\
\hline
\end{tabular}

On the other hand, it can be seen from the variation curves of different sections for ZKA-7 borehole, these curves can be divided into four categories: (1) the spatial variance with less fluctuates and high original scale; (2) the spatial variance with less fluctuates and low original scale; (3) the spatial variance with greatly fluctuates and high original scale; (4) the spatial variance with greatly fluctuates and low original scale.

The curves of these 66 sections $(20-630 \mathrm{~m}, 650-660 \mathrm{~m}, 670-700 \mathrm{~m}, 710-716 \mathrm{~m})$ in the ZKA-7 borehole belong to (2) and (4) categories, the internal variation has no big difference. Variability is more balanced with $10 \%$ fluctuations, which indicates that the 
distribution for the uranium mineralization scale is more uniform, and the original scale average of these sections are relatively low.

The curves of these 4 sections (630-650 m, 660-670 m, $700 \mathrm{~m}$ ) belong to (1) and (3) categories, the internal variation has big difference. Variability has abrupt changes with $60 \%$ fluctuations, which indicates that the distribution of uranium mineralization scale is not balanced, and original scale average of these sections is relatively high, which means that there are anomalies in the sections with such features.

The anomaly sections of the spectrum density curves and the variation curves corresponds to the location of the mineralization body of known geological exploration profile. It can be found that the mineralization anomalies also present in these anomaly sections, and there are distribution signs of metallogenic belt.

It can be seen from Figure 5, abrupt variability usually occurs in the lower section of Zhiluo Formation. According to the size of the original scale value, it can be judged that abrupt sections present strong uranium mineralization information, which indicates that these sections may be gathering zone of uranium mineralization. In order to better verify this explanation, according to the comprehensive distribution characteristics of the spatial variation curves of all boreholes, the anomaly area of A exploration profile was determined, that is, mineralized anomaly area. The determination area is aligned with the mineralized body location map of the known geological profile, as shown in Figure 6. It can be found that the mineralization anomaly region determined by the spatial variation characteristics has relatively better coincidence with the known mineralization zone. So, this determining method can be used as an attempt to determine mineralization anomaly.

Geological section in the A exploration line for Daying Uranium deposits

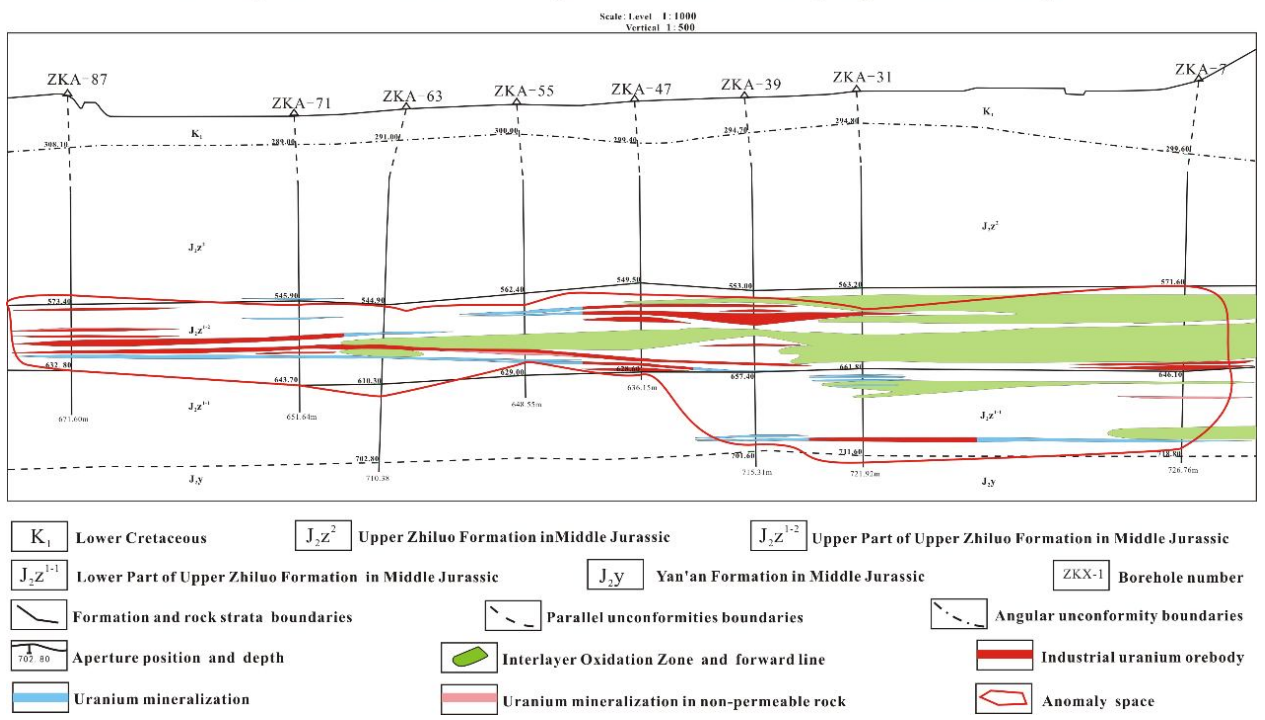

Figure 6. Mineralization anomaly region delineated by the spatial variation characteristics

\section{Conclusion}

The digital spectrum analysis of borehole logging data in Ordos Basin is essentially the fusion analysis of multivariate logging big data. The spatial spectrum density reflects the generalized density of geological elements set, which represents spatial concentration energy intensity of the geological properties. The spatial variation 
function reflects the spatial variation trend of geological element set or uranium mineralization factor. From the digital point of view, these two indicators (spatial spectrum density and spatial variation function) describe the spatial distribution and variation characteristics of the uranium mineralization combination and even mineralization anomalies, which provides a quantitative basis for determining the mineralization anomalies by using the digital features of the geology body

Through the case analysis, it is known that the size of density amplitude and the intensity of density change for the spectrum curves reflect the impact intensity of comprehensive indicators of the geology action. In the case of a larger original scale average, it presents that density amplitude is larger, simultaneously, the zone with greater fluctuations indicates that the comprehensive intensity of uranium mineralization is stronger, and such sections are easy to gather uranium element to achieve the best condition, which is favorable for uranium precipitation mineralization.

The features of spatial variation curves reflect spatial variation degree of the mineralization combined information. The larger original scale average, the greater fluctuations degree and the sections with abrupt change mean that there is a stronger uranium mineralization anomaly information, which indicates that these sections are favorable for forming the uranium mineralization zone, then to determine the spatial range of ore-bearing for A exploration profile. In the four categories of variance curves recognition, (1) and (3) categories indicate the mineralization section, where (3) categories indicates greater significance.

The better coincidence between the mineralization body location map and the mineralization anomaly area determined by the features of spatial spectrum density and variation curves shows that the digital spectrum calculation based on fusion analysis of multiple logging curves can be used as the effective and tentative method for identifying determination anomaly information.

Because data science system is uncertain and the constituent components are unknown, this study only uses known data to describe the unknown information, and uses the correlation between the data to construct the information identification method. This is also the limitation of this study. In order to better improve the limitations, this study can replace the most basic transform method with others, and make the tests. Then it also encrypts the multi-dimensional data density to improve the accuracy and make the result information more refined. The construction of this study belongs to the accurate prediction of the behavior or state of the natural science system. Now, it has been applied in the accurate prediction of geological mineralization, and will develop in the direction of precision medical evaluation and ecological critical identification in the future, this is also the future direction for this study.

Acknowledgements. This research was supported by the National Key Basic Research Program of China (No. 2015CB453005), the National Natural Science Foundation of China (No. 41802245).

\section{REFERENCES}

[1] Ahmed, E.-R., Arnous, M. O. (2015): A novel approach in hydrogeochemical exploration for uranium mineralization: an example from West Central Sinai, Egypt. - Acta Geologica Sinica 6: 1895-1913. 
[2] Cai, Y. Q., Zhang, J. D., Li, Z. Y., Guo, Q. Y., Somg, J. Y., Fan, H. H., Liu, W. S., Qi, F. C., Zhang, M. L. (2015): outline of uranium resources characteristics and metallogenetic regularity in China. - Acta Geologica Sinica 3: 918-937.

[3] Chen, Y. G. (2009): Reconstructing the mathematical process of spatial autocorrelation based on Moran's statistics. - Geographical Research 28(6): 1449-1463.

[4] Cui, H. J., Singh, V. P. (2016): Maximum entropy spectral analysis for streamflow forecasting. - Physica-Statistical Mechanics and Its Applications 442(4): 91-99.

[5] Feng, Z. Q., Liu, D., Huang, S. P., Gong, D. Y., Peng, W. L. (2016): Geochemical characteristics and genesis of natural gas in the Yan'an gas field, Ordos Basin, China. Organic Geochemistry 102: 67-76.

[6] Guo, X., Xue, C. J. (2014): Hydrodynamic regime as a major control on localization of uranium mineralization in sedimentary basins. - Science China 12: 2928-2933.

[7] Hao, G. Q., Yin, Y. P., Wei, A. J. (2015): Characteristics of sand body and mineralization condition of uranium in Zhiluo Formation of Shanghaimiao area of Ordos Basin. Science and Technology of West China 14(8): 27-30.

[8] Hotelling, H. (2012): Analysis of a complex of statistical variables into principal components. - Journal of Educational Psychology 24(6): 417-441.

[9] Jiang, L., Qiu, Z., Wang, Q. C., Guo, Y. S., Wu, C. F., Wu, Z. J., Xue, Z. H. (2016): Joint development and tectonic stress field evolution in the southeastern Mesozoic Ordos Basin, west part of North China. - Journal of Asian Earth Sciences. DOI: 10.1016/j.jseaes.2016.06.017.

[10] Jiao, Y. Q., Wu, L. Q., Rong, H., Peng, Y. B., Maio, A. S., Wang, X. M. (2016): The Relationship between Jurassic coal measures and sandstone-type uranium deposits in the northeastern Ordos Basin, China. - Acta Geologica Sinica 6: 2117-2132.

[11] Khalid, T., White, P., De, L., C. B., Persad, R., Ewen, R., Johnson, E. (2013): A Pilot study combining a GC-sensor device with a statistical model for the identification of bladder cancer from urine headspace. - Plos One 8(7): UNSP e69602.

[12] Lei, J. Y., Yao, Q. F., Lei, Y., Liu, C. (2011): Structural damage detection method based on correlation function analysis of vibration measurement data. - Journal of Vibration and Shock 30(8): 221-224.

[13] Li, B. L. (2012): The Methods Research of Lithology Identification Based on Logging Data. - Xi' an University of Science and Technology, Xi'an.

[14] Li, Z. Y., Huang, Z. Z., Li, X. Z., Guo, J., Fan, C. (2015): The discovery of natural native uranium and its significance. - Acta Geologica Sinica 5: 1561-1567.

[15] Liang, Y., Ma, L., Na, X., Chen, C. (2011): Research of time delay estimation based on GCC algorithm. - Computer Science 38(B10): 454-456.

[16] Liu, D., Zhang, W. Z., Kong, Q. F., Feng, Z. Q., Fang, C. C., Peng, W. L. (2016): Lower PALEOZOIC source rocks and natural gas origins in Ordos Basin, NW China. Petroleum Exploration and Development Online 43(4).

[17] Liu, G. D., Sun, M. L., Zhao, Z. Y., Wang, X. B., Wu, S. H. (2013): Characteristics and accumulation mechanism of tight sandstone gas reservoirs in the Upper Paleozoic, northern Ordos Basin, China. - Petroleum Science 4: 442-449.

[18] Lu, L. J., Liu. W. B. (2015): Digital spectral analysis method of geological space. - ICIC Express Letters 9(6): 1699-1706.

[19] Luo, J. C., Hu, R. Z., Shi, S. H. (2015): Timing of uranium mineralization and geological implications of Shazijiang granite-hosted uranium deposit in Guangxi, South China: new constraint from chemical U-Pb age. - Journal of Earth Science 6: 911-919.

[20] Lv, P., Ding, Z. F., Zhu, L. P. (2011): Application of double-difference relocation technique to aftershocks of 2008 Wenchuan earthquake using waveform crosscorrelation. - Acta Seismologica Sinica 33(4): 407-419.

[21] Ma, K., Vitek, O., Nesvizhskii, A. I. (2012): A statistical model-building perspective to identification of MS/MS spectra with PeptideProphet. - BMC Bioinformatics 13(Suppl 16): 96-103. 
[22] Mariotti, E., Veronese, M., Dunn, J. T., Southworth, R., Eykyn, T. R. (2014): Kinetic analysis of hyperpolarized data with minimum a priori knowledge: Hybrid maximum entropy and nonlinear least squares method (MEM/NLS). - Magnetic Resonance in Medicine 73(6): 2332-2342.

[23] Min, M. Z., Xu, H. F., Chen, J., Fayek. M. (2005): Evidence of uranium biomineralization in sand stone-hosted roll-front uranium deposits, northwestern China. Ore Geology Reviews 26: 198-206.

[24] Silbert, N. H., Thomas, R. D. (2013): Decisional separability, model identification, and statistical inference in the general recognition theory framework. - Psychonomic Bulletin \& Review 20(1): 1-20.

[25] Wang, Y., Yang, W. L., Deng, J., Wu, B. L., Li, Z. Y., Wang, M. Z. (2014): Accumulation system of cohabitating Multi-Energy minerals and their comprehensive exploration in sedimentary basin-A case of Ordos Basin, NW China. - Acta Geologica Sinica 88(5): 815-824.

[26] Wu, B. L. (2005): Geological and Mineralization of Sandstone Type Uranium Deposits in the Mesozoic and Cenozoic Basins in Northwest China. - Northwest University, Xi'an.

[27] Xie, W. D., Zhou, Y. H., Kou, R. L. (2011): An improved fast normalized cross correlation algorithm. - Journal of Tongji University (Natural Science) 39(8): 1233-1237.

[28] Yang, M. H., Li, L., Zhou, J., Jia, H. C., Sun, X., Gong, T., Ding, C. (2015): Structural evolution and hydrocarbon potential of the upper Paleozoic Northern Ordos Basin, North China. - Acta Geologica Sinica 5: 1636-1648.

[29] Yi, C., Gao, H. W., Li, X. D., Zhang, K., Chen, X. L., Li, J. X. (2015): Study on indicative significance of major elements for sandstone-type uranium deposit in Zhiluo Formation in northeastern Ordos Basin. - Mineral Deposits 34(4): 801-813.

[30] Zhang, Q., Zhou, Y. Z. (2017): Big data will lead to a profound revolution in the field of geological science. - Chinese Journal of Geology 52(3): 637-648.

[31] Zhao, Z. Y., Guo, Y. R., Wang, Y., Lin, D. J. (2012): Research progress of tectonic evolution and ancient geographical features of Ordos Basin. - Special Oil and Gas Reservoirs 19(5): 15-20.

[32] Zhou, Y. Z., Li, P. X., Wang, S. G., Xiao, F., Li, J. Z., Gao, L. (2017): Research progress on big data and intelligent modelling of mineral deposits. - Bulletin of Mineralogy, Petrology and Geochemistry 36(2): 334-339.

[33] Zhou, Y. Z., Chen, S., Zhang, Q., Xiao, F., Wang, S. G., Liu, Y. P., Jiao, S. T. (2018): Advances and prospects of big data and mathematical geoscience. - Acta Petrologica Sinica 34(2): 256-263.

[34] Zhu, L. (2013): Research of visualization and analysis methods of logging data. - Wuhan Institute of Technology, Wuhan. 